\title{
DERECHO Y POLÍTICAS AMBIENTALES EN EXTREMADURA (SEGUNDO SEMESTRE 2020)
}

\author{
PEDRO BRUFAO CURIEL \\ Profesor Titular Doctor de Derecho Administrativo \\ Universidad de Extremadura
}




\section{Novedades jurídicas en el Derecho Ambiental extremeño}

En esta entrega sobre el Derecho y la política ambiental extremeños, indicamos la publicación de medidas contra especies que se consideran dañinas, como aplicación de la excepción general al principio general de conservación de las especies silvestres, ya sean o no objeto de aprovechamiento.

En primer lugar, contamos con la Orden de 4 de mayo de 2020 sobre las normas de control durante 2020 de la langosta mediterránea, que se ampara en el RD 1507/2003, de 28 de noviembre, por el que se establece el programa nacional de control de las plagas de langosta y otros ortópteros, cuyo art. 4 establece que las Comunidades Autónomas en las que existan poblaciones endémicas de plagas de langosta u otros ortópteros efectuarán prospecciones anuales en las épocas adecuadas para determinar la presencia de dichas plagas, así como, en su caso, para delimitar los lugares de puesta o las zonas de avivamiento.

Esta Orden se ampara en la normativa contra plagas de la Ley 43/2002, de 20 de noviembre, de Sanidad Vegetal, el RD 1311/2012, de 14 de septiembre, por el que se establece el marco de actuación para conseguir un uso sostenible de los productos fitosanitarios y el Decreto extremeño 138/1994, de 13 de diciembre, por el que se establecen las bases de actuación en las campañas oficiales fitosanitarias, que comprenden como "campaña oficial de tratamientos fitosanitarios" bajo el control de las autoridades de Sanidad Vegetal el tratamiento aéreo y terrestre de la langosta mediterránea con deltametrín 2,5 $\%$, tanto para el tratamiento de las ninfas como de los insectos adultos. Con esta Orden se regulan las condiciones en las que la lucha contra la langosta mediterránea de los propietarios y arrendatarios de fincas de los noventa municipios del anexo, medidas que se fomenta por la Comunidad Autónoma y cuyos agentes cuentan con la potestad del acceso a las fincas. Sin embargo, hay que considerar a su vez el alimento que estos insectos supone para la avifauna de las zonas pseudoesteparias, como los Llanos de Cáceres o La Siberia, fuente de alimento indispensables para especies como la avutarda, el sisón, la ortega, el cernícalo primilla, el mochuelo o la perdiz. Esta cuestión se ha criticado por algunas entidades como SEO/Birdlife, que ha publicado que 
estos tratamientos se aplican incluso sin que se alcancen los umbrales oportunos de incremento de la langosta para aplicar estos insecticidas ${ }^{1}$.

Sobre la protección de la avifauna y el grave problema de las nuevas plantaciones de olivar en "superintensivo" (largas filas de setos de olivos en regadío de tratamiento y recolección mecanizada de aceituna), cuya recogida mecánica nocturna provoca elevadas mortandades de aves que allí encuentran refugio, se ha publicado la Resolución de 5 de agosto de 2020, de la Dirección General de Sostenibilidad, por la que se suspende de manera cautelar la recogida nocturna por medios mecánicos de aceituna en olivares superintensivos por posible daño a aves silvestres, a partir del 1 de septiembre de 2020 hasta el 1 de septiembre de 2021, mediante el uso de cosechadoras cabalgantes entre la puesta de sol y la salida del mismo establecidas por el Instituto Geográfico Nacional para cada localidad y para cada día del año. Otra cuestión es el fomento público del desarrollo del regadío de una plantación de secano y que hace que el tradicional, el que alberga resultados notables para el desarrollo sostenible de zonas deprimidas, no pueda competir en precios en uno de los productos reclamo del consumidor: el aceite de oliva.

Resulta inevitable hablar de la pandemia y, aprovechando esta situación, sin ninguna vinculación lógica y una evidente falta de motivación jurídica, se publicó la Resolución de 6 de mayo de 2020 de la Dirección General de Política Forestal, por la que se procede a autorizar las acciones excepcionales por daños ocasionados por jabalíes y conejos, debido principalmente, se dice, a la menor presencia humana durante el confinamiento y bajo el amparo del RD $463 / 2020$, de 14 de marzo, por el que se declaró el estado de alarma para la gestión de la situación de crisis sanitaria ocasionada por la COVID-19. Esta medida tuvo su continuación gracias a la Resolución de 12 de mayo de 2020 del mismo órgano.

Bajo la pandemia, también se ha hecho uso, o abuso, de la figura del decretoley ${ }^{2}$ para situaciones que por su naturaleza se prolongan en el tiempo. En efecto, el Decreto-Ley 10/2020, de 22 de mayo, de medidas urgentes para la

\footnotetext{
1 Vid. https://www.seo.org/2017/03/22/posible-disminucion-de-poblaciones-de-insectos-en-extremadura/ [Consulta realizada el 14 de octubre de 2020].

${ }^{2}$ BRUFAO CURIEL, P., "Gobernar mediante decreto-ley en España: cuando la excepción se convierte en norma", Ars Boni et Aequi, vol. 14, núm. 2, 2018.
} 
reactivación económica en materia de edificación y ordenación del territorio destinadas a dinamizar el tejido económico y social de Extremadura, para afrontar los efectos negativos de la COVID-19. En efecto, se dice en esta norma que "los costes de oportunidad derivados de la dilación de las medidas pueden ser enormes, por lo cual se debe procurar evitar toda la burocracia innecesaria y generar un cambio del paradigma de control: descentralización de trámites, eliminar controles innecesarios, flexibilizando los controles ex-ante. La rápida aplicación de las medidas es uno de los principales elementos para el logro de la eficacia de las mismas". Lo aquí transcrito olvida lo obvio: el que esas situaciones se prolongarán en el tiempo $\mathrm{y}$, por tanto, no les sea de aplicación la interpretación extensiva de la figura de esta fuente excepcional del Derecho. Se llega incluso, sin pudor, a ligar bajo la pandemia el cambio climático y la lucha contra la despoblación, con los usos territoriales generales a largo plazo que conllevan, algo que carece de toda base jurídica ante un decreto-ley, cuyos efectos tendrán lugar más allá de la duración de la pandemia.

Las medidas que incluye reforman nada menos que la reciente Ley $11 / 2018$, de 21 de diciembre, de ordenación territorial y urbanística sostenible de Extremadura (LOTUS), y tienen como características lo siguiente:

- Flexibilizan la implantación de usos en edificios, facilitando el ejercicio en ellos de todo tipo de actividades y profesiones.

- Eliminan, para los nuevos desarrollos de usos industriales o terciarios en el suelo urbanizable, los condicionantes establecidos en cuanto a estándares mínimos de los que debe gozar el núcleo de población para poder clasificar nuevo suelo como urbanizable, facilitando con ello nuevos desarrollos industriales o terciarios en el suelo urbanizable.

- Consideran, elevando su categoría, a las ordenanzas municipales de edificación y urbanización y a las normas técnicas de planeamiento como instrumentos no ya de desarrollo del planeamiento, sino como instrumentos que contribuyen a la ordenación urbanística.

- Alteran el ámbito de las competencias entre municipios y la comunidad autónoma en el caso de las autorizaciones en suelo rústico. Se eximen así las 
actividades agropecuarias, cinegéticas, forestales, piscícolas o análogas, todas ellas vinculadas a la naturaleza del terreno, del requisito de obtener calificación rústica, en todo caso y circunstancia.

- Se flexibiliza la exigencia de parcela mínima para el uso terciario de estaciones de servicio y del uso agropecuario que podrán autorizarse con una menor superficie de suelo vinculada. Al mismo tiempo, se crean los medios para regularizar miles de construcciones ilegales, gracias a la incorporación de los edificios al mercado normal de transacciones inmobiliarias y permitiendo, una vez regularizados, las obras de mantenimiento y, en su caso ampliación, que requiere habitualmente cualquier edificación. Es decir, se prevé una nueva legalización de construcciones ilegales en suelo rústico, objeto único real de las reformas sucesivas leyes del suelo de la región, a lo cual se suma la aplicación directa del régimen urbanístico de las distintas clases de suelo de la LOTUS a los municipios con planes vigentes y no adaptados a la misma. En conclusión: las sucesivas legalizaciones no han conseguido frenar el fenómeno generalizado de las construcciones ilegales, pues como es obvio, incentivan la actividad urbanística clandestina con la esperanza de una hipotética legalización.

Asimismo, esta norma excepcional y temporal regula cuestiones estables relativas al aprovechamiento subjetivo en casos de rehabilitación, regeneración y renovación urbanas. También reduce el plazo máximo para el procedimiento de otorgamiento de licencia de primera ocupación o utilización estableciendo un régimen de silencio positivo, con el fin, se dice, de incentivar a los ayuntamientos a agilizar la concesión de este tipo de licencias. También se amplía el plazo dado por la LOTUS para la aprobación definitiva de los planes territoriales y sus modificaciones en vigor. $\mathrm{Y}$ de modo muy importante, altera profundamente el concepto de suelo rústico para que puedan acogerse múltiples actividades económicas.

Tiene efectos incluso retroactivos, algo inexplicable y claramente inconstitucional en un decreto-ley: no recibirán el tratamiento de actuaciones disconformes y se considerarán con licencia a todos los efectos las actividades que, manteniendo su uso, se hubieran implantado con anterioridad al año 1975, por lo que, como consecuencia, podrán cambiar su uso, ejecutar obras de 
consolidación o adaptación, que les permitan continuar con su funcionamiento efectivo.

En la misma línea del abuso de la figura del decreto-ley y de eliminación del control administrativo, se publicó el Decreto-Ley 12/2020, de 19 de junio, de medidas extraordinarias y urgentes para la reactivación de la actividad económica y social en la Comunidad Autónoma de Extremadura en el proceso hacia la "nueva normalidad". Destaca la eliminación de la licencia urbanística, la de obra y la de usos provisionales para los proyectos empresariales de interés autonómico, sustituidas por un mero trámite de consulta. De forma muy grave, altera el cambio de uso forestal a agrario, algo que ya se observa con la simple lectura del DOE, por lo que no tendrán carácter excepcional ni será vinculante el informe del órgano forestal para ciertos cambios de uso forestal para los que no es necesaria la evaluación de impacto ambiental, en zonas de alto riesgo de incendios o que se encuentren en términos municipales que padezcan desventajas demográficas. Hay que decir por último que esta norma cuenta con características propias de las leyes de presupuestos, que se suelen aprovechar para reformar cuestiones muy dispares, ejemplo conocido de leymedida, pues además se incluyen reformas en materia de transportes o contratación pública, por citar algunos ejemplos.

Sobre el medio ambiente laboral, se ha publicado el Decreto 58/2020, de 6 de octubre, por el que se establece la forma de presentación de la declaración de actividades laborales con exposición a la radiación natural en la Comunidad Autónoma de Extremadura y regula el registro de las mismas. Este asunto es especialmente grave por los efectos de la acumulación natural del radón en zonas graníticas, muy abundantes en Extremadura. Su objeto incluye medidas sobre las actividades laborales expuestas a la inhalación de descendientes de torón o de radón o a la radiación gamma o a cualquier otra exposición en lugares de trabajo tales como establecimientos termales, cuevas, minas, lugares de trabajo subterráneos o no subterráneos en áreas identificadas; las actividades laborales que impliquen el almacenamiento o la manipulación de materiales o de residuos, incluyendo las de generación de éstos últimos, que habitualmente no se consideran radiactivos pero que contengan radionucleidos naturales que provoquen un incremento significativo de la exposición de los 
trabajadores y, en su caso, de miembros del público; y, finalmente las actividades laborales que impliquen exposición a la radiación cósmica durante la operación de aeronaves.

Estas son las principales reseñas dignas de incluir en esta crónica extremeña. 